\title{
Rock Physics Interpolation Used for Velocity Modeling of Chalks: Ontong Java Plateau Example
}

\author{
Mohammad Reza Saberi*, Tor Arne Johansen and Gunnar Sælen
}

Department of Earth Science, University of Bergen, N-5007 Bergen, Norway

\begin{abstract}
Chalks are pelagic carbonate sediments that are deposited in deep-water environments. Their elastic behaviour is controlled by a combination of depositional conditions and subsequent diagenesis. In this paper, we incorporate geological information into rock physics modeling by constraining the pore structure (aspect ratio) variability. The strategy is to define a pore-model that reflects lithology, porosity and velocity. Then, a background velocity cube is constructed based on information about the lithologies and the velocity data from some reference wells. This approach may be further used to obtain a gridded velocity model of a reservoir sequence.

Well and core data from 14 wells on the Ontong Java Plateau, obtained through the deep sea drilling program and the ocean drilling program, are used to examine this approach. Velocity predictions based on the pore-models derived from six reference wells in the area, show a good correlation with measured velocities at some blind wells. This indicates a homogeneous and predictable pore structure in the area.
\end{abstract}

Keywords: Pelagic carbonates, modeling, reservoir characterization, rock physics, velocities.

\section{INTRODUCTION}

In order to create a subsurface image using seismic measurements we need to understand the details of elastic wave propagation in the subsurface. Based on the interpretation of these images, we wish to extract information about the burial depth of geological structures as well as their lithofacies and pore fluids. Such detailed information necessitates the integration of seismic data and parameters describing the lithology and reservoir properties. The major goal of a rock physics model is to establish a correlation between these parameters, and, thus, to understand how lithology, porosity, pore type, pore fluid and saturation etc. influence the velocities and attenuations of Pand $\mathrm{S}$-waves in sedimentary rocks, and ultimately use this information for inverse modeling. While porosity is the main velocity-controlling factor in siliciclastic rocks, pore type is an equally important velocity-controlling factor in carbonates [1].

Chalks are pelagic carbonate sediments that were deposited in deep-water environments. The petrophysical and elastic properties of chalks are controlled by the overall porosity reduction resulting from post-depositional processes [2]. The relationship between P-wave velocity, porosity, and burial depth has been discussed widely by other authors (e.g. [3-8]).

Audet [4] used a theoretical compaction curve based on soil mechanics theory to explain the observed trends in porosity and velocity versus depth for the normally pressured oozes and chalks in the Ontong Java Plateau, while Japsen

*Address correspondence to this author at the Department of Earth Science, University of Bergen, N-5007 Bergen, Norway;

Tel: +47-48350591; Fax: +47-55583660;

E-mails: mohammad.saberi@geo.uib.no,reza_zeydan@yahoo.com
[5] investigated such relationships for overpressured chalk anomalies in the North Sea. However, Fabricius [6] related diagenesis (burial effects) of chalk sediments to elastic Pwave modulus by construction of a series of isoframe curves, where isoframe values can be related to the Biot coefficient [8]. Biots coefficient relates to the pore space compressibility as it is the ratio of pore volume change to bulk volume change at constant pore pressure [9]. As has been pointed out by Gommesen et al. [7], this parameter is important for describing the elastic behaviour of chalks. Saberi et al. [10] considered the diagenetic model of Fabricius [6], to model the elastic parameters of chalks by defining different pore-models at various diagenetic stages (ooze, chalk, limestone). They investigated the impact of the various pore-models on chalk velocities (Fig. 1) and related them to the pore space compressibility using so called poremodel stiffness parameter [10].

In this paper, we adopt the procedure used by Saberi et al. [10] who defined pore-models based on measured velocity and porosity data obtained from some wells (reference wells) on the Ontong Java Plateau. These poremodels are subsequently used to predict chalk velocities at locations far away from the reference wells, assuming a prior knowledge of burial depths and lithofacies.

The Ontong Java Plateau is a huge oceanic plateau located in the Pacific Ocean (Fig. 2) with a sequence of deep-sea carbonate sediments ranging from carbonate ooze to chalks to limestone [11]. The modelled velocity of the pelagic carbonates of the plateau can be further used to build a background velocity cube important for seismic characterization of the sediments. Comparison of such background velocity models to a seismically defined velocity cube may pinpoint seismic anomalies reflecting local diagenetic features or variations in the initial depositional conditions. 
(a)

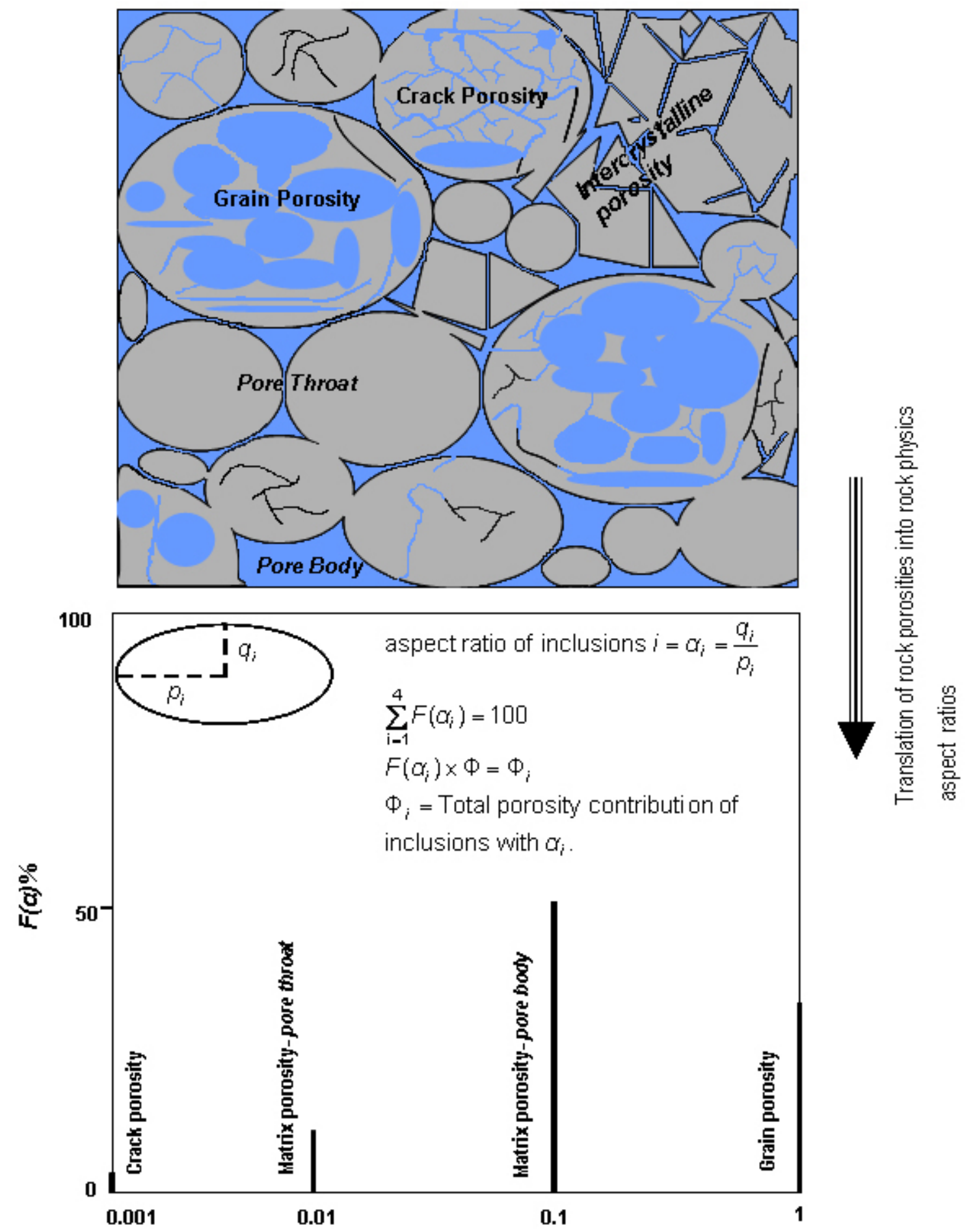

(b)

(a)

Fig. (1). Illustration of (a) different pore types and (b) related pore-models in chalks. Grain porosity make up the void portion of the foraminifera tests with aspect ratio $(\alpha)$ and concentration equal 1 and $F(1)$, respectively. Matrix porosity (pore-body), Matrix porosity (porethroat), and crack porosity are part of the matrix texture and have aspect ratios of 0.1-0.9, 0.01 and 0.001 , and concentrations of $F(0.1-0.9)$, $F(0.01)$, and $F(0.001)$, respectively. Intercrystalline porosity can be expressed as pore body and pore throat. 0.1-0.9 shows stiffening behavior of pore body aspect ratios that vary with depth from 0.1 (ooze interval) to 0.9 (deep limestone) and $\Phi$ i is the porosity contribution of each pore types in the total porosity. Saturated crack porosity is in blue and unsaturated one in black. (after Saberi et al. [10]).

First, a brief review of the main depositional and diagenetic environments (including porosity trends) of chalks are given, followed by the detailed approach for modeling their velocities [10]. Laboratory data of porosity, velocity and composition from six reference wells are used to obtain the pore structure variations which then served as a 


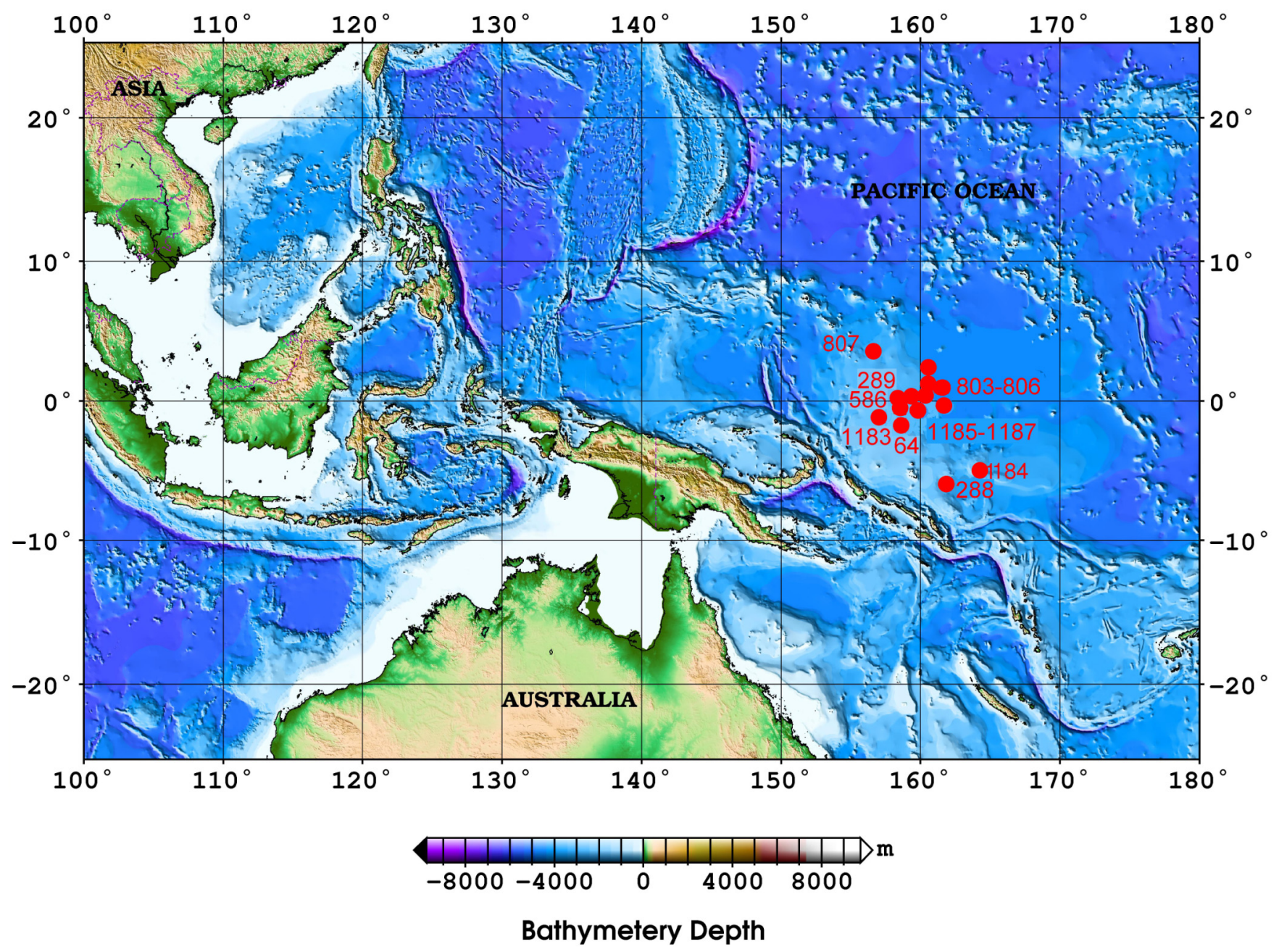

Fig. (2). Bathymetric map of the Ontong Java Plateau. Wells drilled into the plateau during the deep sea drilling program and ocean drilling program are shown as red circles (map is generated using Generetic Mapping Tool (GMT) and bathymetric data are from Smith and Sandwell [40]).

background pore-model. This background model is then used for prediction of velocities at seven blind well positions, i.e. wells not used when defining the background model.

\section{CHALK DEPOSITION AND DIAGENESIS}

Chalks are deposited in deep-water environments and largely consist of stable low-magnesium calcite (e.g. [2]). Their sedimentation is relatively simple, involving only deposition from suspensions and vertical aggradation of mainly planktonic algae (coccolithophores), and zooplankton (e.g. foraminifera). These mixtures of the skeletal components of predominantly $0.25-1 \mu \mathrm{m}$-size coccolith debris and 50-100 $\mu \mathrm{m}$-size foraminifera [12] are modified by biological, chemical and circulation factors within the oceanic water column and on the sea floor to form soft, water-rich sediments referred to as pelagic ooze. The texture and composition of these sediments, as with other carbonates, are very sensitive to changes in oceanographic conditions and such changes result in variations in reservoir properties. Thus, texture and composition of the pelagic oozes may reflect changes in numerous factors, including water temperature, salinity and nutrients as well as water depth $[3,13]$. Ooze deposits are normally bioturbated, and their biogenic constituents may be variably dissolved below the aragonite or calcite lysoclines, or become vastly cemented at the seafloor above these depths. Moreover, bioturbation combined with microbially mediated processes may ultimately lead to the formation of hard-grounds. Hardground formation reduces the porosity of pelagic carbonate sediments drastically but they rarely affect a thick sedimentary section [14]. On the other hand, reworked chalks (slumps and debris flows) may have porosities in excess of $50 \%$ (e.g. [15]).

In the shallow subsurface, ooze porosity is reduced by mechanical compaction including dewatering, re-orientation and breakage of grains. This depth interval is commonly referred to as the ooze interval [16]. In this interval, mechanical compaction forms a more rigid rock frame [17] and we may have contact cementation [6]. Once the carbonate sediment has been mechanically compacted, and a stable grain framework has been established, continued burial will decrease porosity further by chemical compaction, recrystallization and cementation. This interval is known as the chalk interval where chemical compaction provides cement and, thus, porosity loss [2], while recrystallization implies simultaneous dissolution and 
reprecipitation processes so that some fossil fragments will become larger and smoother. The latter process does not cause porosity loss, but makes the calcite crystals to be more equant and smooth and, in this way, furthers compaction $[6,18]$.

These processes continue with depth, in the limestone interval by introduction of large amounts of cement into the pore spaces from inside (continued pressure dissolution) or outside sources (like cements from the outside fluids). The pore-filling low-Mg calcite cement is the main porosityreducing agent in the limestone interval [6]. This progressive diagenesis (ooze-chalk-limestone) has been addressed by many authors and includes changes in the pore geometry $[10,19]$ as well as the reduction in porosity (e.g. [2,16,17,20,21]). Saberi et al. [10] showed how we can incorporate the effect of these changes into rock physics characterization of the chalks (Fig. 1).

\section{POROSITY AND PORE-MODEL}

Pelagic oozes normally have high critical porosity, varying between 55 and $85 \%[2,3,6,17]$, depending on sorting and texture. These high values of the critical porosity are mainly related to the ooze spherical structure, which is similar to that of sandstones [22], and to their foraminifera content [6]. Positive correlations between foraminifera content and porosity, mean grain size and velocity have already been explained by other authors [3,4,6]. This is further confirmed by scanning electron microscopy images that show intragrain porosity within foraminifera tests [23]. Hamilton et al. [3] reported a porosity of hollow foraminiferal test of about $80 \%$, which refers to the intragrain porosity. Based on these facts, Saberi et al. [10] divided chalk porosity classes according to their potential influence on seismic velocities (Fig. 1) into three main groups,

1. Grain porosity is defined as the void space inside foraminifers that is considered to be insensitive to pressure changes with aspect ratio $(\alpha)$ equal to 1 .

2. Matrix porosity makes up the majority of the interparticle porosity and comprises the intercoccolith and inter-crystalline pore space. This pore space is furthermore divided into larger pore-body $(\alpha=0.1-0.9)$ and narrower pore-throat $(\alpha=0.01)$ pore spaces. The matrix porosity strongly depends on the overburden pressure.

3. Crack porosity with $\alpha=0.001$ represents the very compliant parts of the porosity such as cracks, flat pores and the grain contact area (see Saberi et al. [10]).

Coccoliths and foraminifers form the major part of the porosity, while cracks and fractures are added because they potentially have a large influence on acoustic wave propagation. Therefore, the crack porosity constitutes only a small fraction in the total porosity but has a significant influence on velocity [24]. Fig. (1) shows a conceptual figure of porosity classification of chalks and related rock physics parameters, compiled from Saberi et al. [10].

The porosity classification is defined at each depth point, $\mathrm{m}$, by the pore-model $P_{m}(\hat{\alpha}) . P_{m}(\hat{\alpha})$ is defined by four aspect ratios $\left(\alpha_{i}, \mathrm{i}=1-4\right)$ and their corresponding volume fractions $\left(F_{m}\left(\alpha_{i}\right), \mathrm{i}=1-4\right)$ in Fig. (1b). At each modeling point $\mathrm{m}, P_{m}(\hat{\alpha})$ are defined by

$$
P_{m}(\hat{\alpha})=\left\{\left(\alpha_{1}, F_{m}\left(\alpha_{1}\right)\right),\left(\alpha_{2}, F_{m}\left(\alpha_{2}\right)\right),\left(\alpha_{3}, F_{m}\left(\alpha_{3}\right)\right),\left(\alpha_{4}, F_{m}\left(\alpha_{4}\right)\right)\right\},
$$

where

$$
\sum_{i=1}^{4} F_{m}\left(\alpha_{i}\right)=100 \%
$$

Note that the volume fraction of each pore shape, $\Phi_{i}$, is given in percent of total porosity $\Phi$. Thus, $\Phi_{\mathrm{i}}=F_{m}\left(\alpha_{i}\right) * \Phi$ is the volume fraction of the total porosity made up by inclusions of aspect ratio $\alpha_{i}$. Diagenesis which often is associated with breaking of grains, evolving crack porosity and mechanical and chemical compaction transforms $P_{0}(\hat{\alpha})$ (depositional state) to $P_{m}(\hat{\alpha})$ (depth point $\mathrm{m}$ ). Saberi et al. [10] discussed a procedure to define $\alpha_{i}$ and $F\left(\alpha_{i}\right)$ related to textural and burial effects of chalks.

\section{ROCK PHYSICS MODELING}

Revealing the appropriate rock physics properties is important in reservoir characterization because they make a link between seismic velocities and rock properties, and, thus, may connect seismic attributes to reservoir parameters. We can study the elastic moduli of a mixture of grains of various properties by either empirical or theoretical relations. Empirical relations like the time average of Wyllie et al. [25] define $\mathrm{P}$ velocities only from the volume fractions of the various constituents and their velocities. Knowing the elastic moduli and volume fractions only enable us to predict the lower and upper elastic bounds like boundaries defined by Reuss [26] and Voigt [27]. If we want to predict the effective elastic properties related to various geometric details of the constituents (grains and pores), we need to apply other methods, e.g. inclusion based models. In the following, we will use a self-consistent approach (SCA) $[28,29]$ in order to understand the velocity behaviour within the Ontong Java Plateau.

Furthermore, we examine the use of the time average equation of Wyllie et al. [25], the models of Reuss [26] and Voigt [27], and the Hashin-Shtrikman [30] (HS) bounds.

The time average equation expresses the effective $\mathrm{P}$ velocity $\left(V_{p}\right)$ by

$$
\frac{1}{V_{P}}=\frac{(1-\Phi)}{V_{P, \text { matrix }}}+\frac{\Phi}{V_{P, \text { fluid }}} \text {. }
$$

The Reuss bound [26] defines the elastic moduli from the harmonic average by

$$
\frac{1}{K}=\frac{(1-\Phi)}{K_{\text {matrix }}}+\frac{\Phi}{K_{\text {fluid }}},
$$

so that $\mu=0$, when $\mu_{\text {fluid }}=0$ (suspension limit), while the Voigt bound [27] defines the arithmetic mean, i.e.

$$
\begin{aligned}
& K=(1-\Phi) K_{\text {matrix }}+\Phi K_{\text {fluid }}, \\
& \mu=(1-\Phi) \mu_{\text {matrix }} .
\end{aligned}
$$


Here, $K$ and $\mu$ denote bulk and shear modulus and the subscripts matrix and fluid denote the relevant parameters of the matrix or fluid, respectively.

On the other hand, the HS bounds define upper and lower bounds for coated grains. The lower bound $(H S)$ is when the stiffer material is coated by the softer material, while the upper bound $\left(H S^{+}\right)$is when the softer material is coated by the stiffer one. They are defined as [30],

$$
\begin{aligned}
& K^{t S S}=K_{1}+\frac{f_{2}}{\left(K_{2}-K_{1}\right)^{-1}+f_{1}\left(K_{1}+\frac{4}{3} \mu_{1}\right)^{-1}}, \\
& \mu^{t S}=\mu_{1}+\frac{f_{2}}{\left(\mu_{2}-\mu_{1}\right)^{-1}+\frac{2 f_{1}\left(K_{1}+2 \mu_{1}\right)}{5 \mu_{1}\left(K_{1}+\frac{4}{3} \mu_{1}\right)}} .
\end{aligned}
$$

where $K_{1}$ and $K_{2}$ are the bulk modulus of each phases, $\mu_{1}$ and $\mu_{2}$ are the shear modulus of each phases, and $f_{1}$ and $f_{2}$ are volume fractions of each phases in a two-phase mixture. Upper and lower bounds are defined by interchanging the subscripts 1 and 2. The upper bound is realized when the stiffer material act as a shell on the soft material and vice versa.

These estimates can be improved using inclusion based models when the geometries of the various constituents (e.g. pore-model) are specified. First order scattering models (e.g. [31]) are restricted to handle a dilute volume fraction of pores (lower porosity rocks), while SCA mimics the effects of second and higher order scattering terms due to pore to pore interactions. SCA is used to study a fluid containing solid grains or solid containing fluid-filled pores. However, the pore to pore interactions are elastic and not due to fluid flow. Berryman [28,29] formulated SCA for porous rocks where a uniform host material is randomly embedded with spherical and/or ellipsoidal inclusions. The effective volume of density $\left(\rho^{*}\right)$, bulk modulus $\left(K^{*}\right)$ and shear modulus $\left(\mu^{*}\right)$ of a solid including $N$ families of inclusions of aspect ratio $\alpha_{i}$ are given as [28,29].

$$
\begin{aligned}
& \rho^{*}=(1-\Phi) \rho_{m}+\sum_{\mathrm{i}=1}^{\mathrm{N}} \Phi_{\alpha} \rho_{\mathrm{i}}, \\
& \sum_{i=1}^{N} \Phi_{\alpha}\left(K_{i}-K^{*}\right) P^{* i}=0,
\end{aligned}
$$

and

$$
\sum_{i=1}^{N} \Phi_{\alpha}\left(\mu_{i}-\mu^{*}\right) Q^{* i}=0
$$

Here, $P^{*_{i}}$ and $Q^{*_{i}}$ are tensors which depend on the material properties of the matrix and the inclusion material as well as the aspect ratios of the inclusions. Formulae for inclusions of prolate, oblate spheroids or disc shapes can be found in Berryman $[28,29]$. The SCA method is a high frequency approximation [9] and predicts percolation limits at critical porosity. It simulates a high-frequency saturated rock behavior (no fluid flow) and is therefore considered
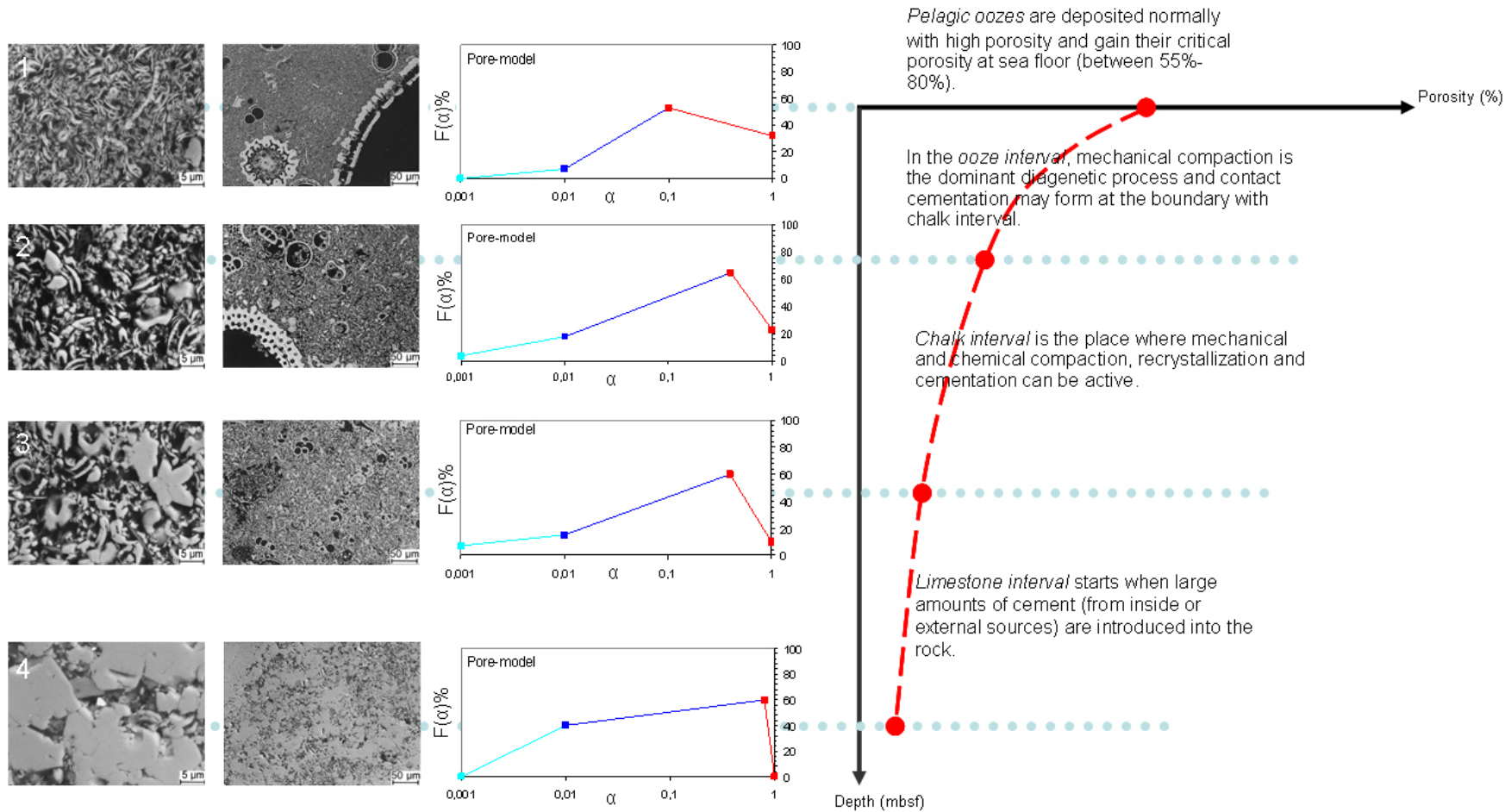

Fig. (3). Diagenetic model of chalks. Mechanical compaction reduces porosity and stiffens the frame in the ooze interval. Mechanical and chemical compaction and cementation reduce porosity in the chalk interval. In the limestone interval, cementation is the dominant postdepositional process where calcite crystals are formed in the rock. Images show backscattered electron micrographs from different depths at site 807 (after Borre and Fabricius [16]): (1) depth: 10 mbsf, porosity: 69\%; (2) depth: 319 mbsf, porosity: 57\%; (3) depth: 919 mbsf, porosity: 49\%; (4) depth: 1127 mbsf, porosity: 17\% (Compiled from Saberi et al. [10]). The pore-model changes with increment in depth are shown from measured data. The compaction curve (red dashed line) is schematic. $\alpha$ is the aspect ratio and $F(\alpha)$ is the aspect ratio concentration. 
appropriate for studying ultrasonic laboratory conditions. More sophisticated methods for taking into account fluid flow in between pores like the T-matrix approach [24,32,33] can also be considered. The T-matrix approach takes into account anisotropy, global and local fluid-flow effects and various degrees of connectivity between pores. However, in this study, we reduce the complexity to only consider effects of various pore classes. The simplicity of applying SCA for this purpose is therefore honored.

\section{ONTONG JAVA PLATEAU VELOCITY MODELING}

The Ontong Java Plateau in the western equatorial Pacific is a broad mid-oceanic submarine plateau striking northwest and paralleling the Solomon Islands to the south [34]. It covers an area of ca $2 \times 10^{6} \mathrm{~km}^{2}$ with a thick column of pelagic carbonates which holds no accumulation of hydrocarbons. The collision of this plateau with the old Solomon arc resulted in uplift of the Ontong Java Plateau's southern margin (Figs. 2, 4). This section includes a brief description of the data set used, followed by the proposed workflow for building a velocity cube for the Ontong Java Plateau using SCA.

Ooze, chalk, and limestone samples have been cored and widely analyzed for porosity and P-velocity, among several other parameters, as a part of the deep sea drilling and ocean drilling programs; site 64 (Leg 7), sites 288 and 289 (Leg
30), site 586 (Leg 89), sites 803-807 (Leg 130) and sites1183-1187 (Leg 192) (Figs. 2, 4). Our data set comprises initial reports and online sources from the 14 wells (sites) drilled into the Ontong Java Plateau during these programs. It includes different experiments for estimating volume percentage of foraminifera (smear slide analysis), weight percentage of carbonate (carbonate geochemistry analysis), porosity and bulk density, as well as horizontal P-velocity measurements. Onboard the ships, ultrasonic velocities of sediment cubes, cut from the cores, were measured using an ultrasonic signal $(400-500 \mathrm{kHz})$ [35]. Therefore, high frequency models like SCA are considered applicable for the subsequent velocity modeling. An SCA model is based on a priori knowledge of the pore shapes (aspect ratios). By fitting the SCA model, with an assumed volumetric distribution of pore types to velocity and porosity data (laboratory), subsequently makes it possible to establish pore type models consistent with the velocity and porosity profiles. This procedure assumes either input of pore type from image analysis or a theoretical distribution of pore types related to primary chalk composition and subsequent alteration during burial [10].

In this paper, the same procedure of Saberi et al. [10] for pore aspect ratio modeling (Fig. 5, stage 1) is applied on six reference sites $(288,289,806,807,1183$ and 1184) on the Ontong Java Plateau to obtain a spatially varying pore-model

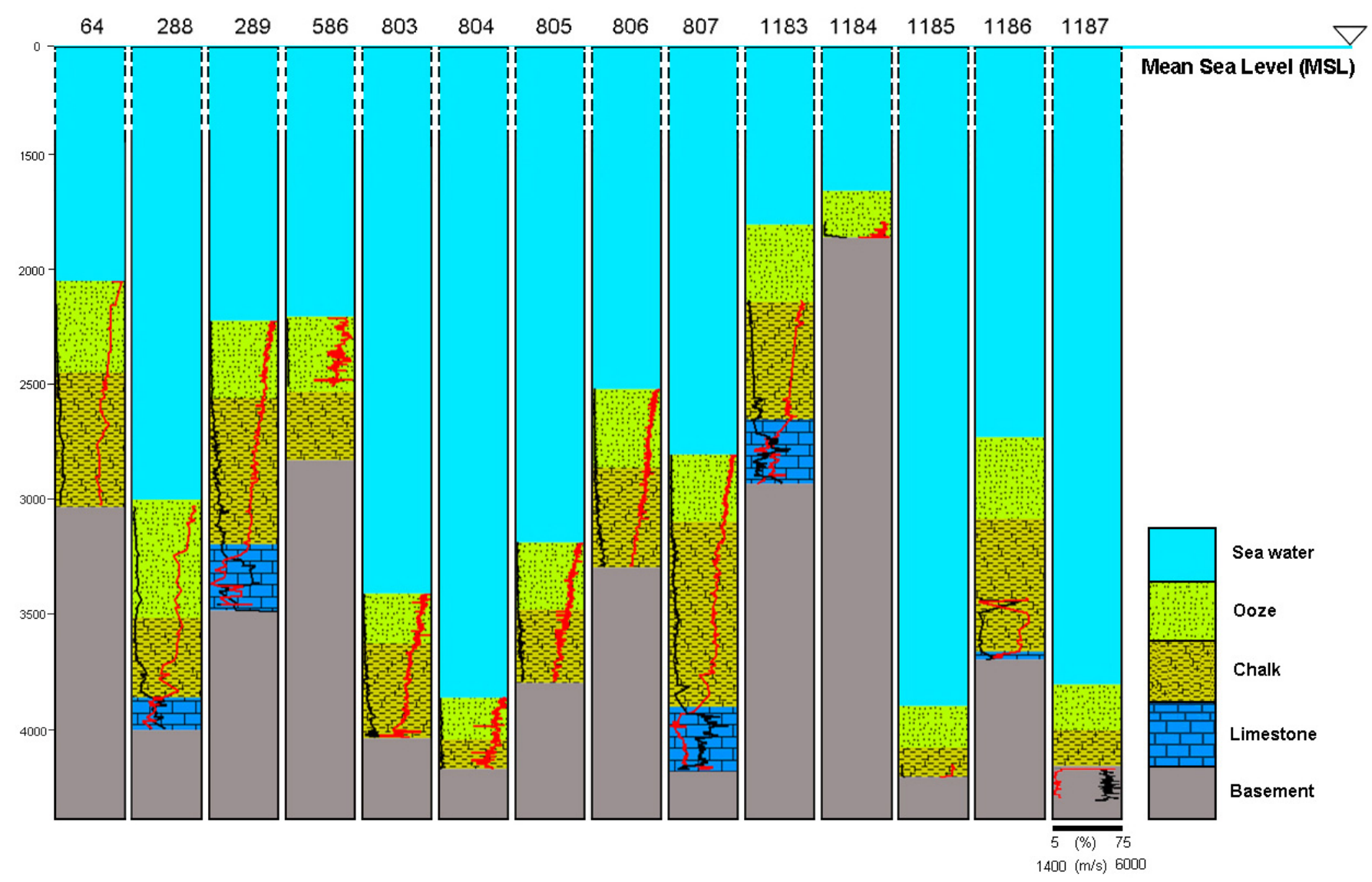

Fig. (4). Cross section of the drilled wells during the deep sea drilling and ocean drilling projects on the Ontong Java Plateau. The location of the area is given in Fig. (2). Available plug velocity (black line) and plug porosity measurements (red line) shown for each well. Porosity and velocity measurements were not available for the sedimentary rocks at site 1187 . Ooze, chalk and limestone thicknesses are determined from core reports [11,34,36-38]. 


\section{STAGE 1: Pore aspect ratio modeling}

Following Saberi et al. [10] procedure, velocity and porosity data of six reference wells $(288,289$, $806,807,1183$ and 1184 ) are used to determine the pore-models at some predefined modeling points (Fig. 6)

\section{STAGE 2: Geo- and property modeling}

Ooze, chalk and limestone thicknesses from all the wells $(64,288,289,586,803,804,805,806$, $807,1183,1184,1185$ and 1186 ) are used to build a simple gridded model. The pore-models determined in the stage 1 along with the pore-model stiffness (PMS) value, are now distributed within the grids using the moving average algorithm.

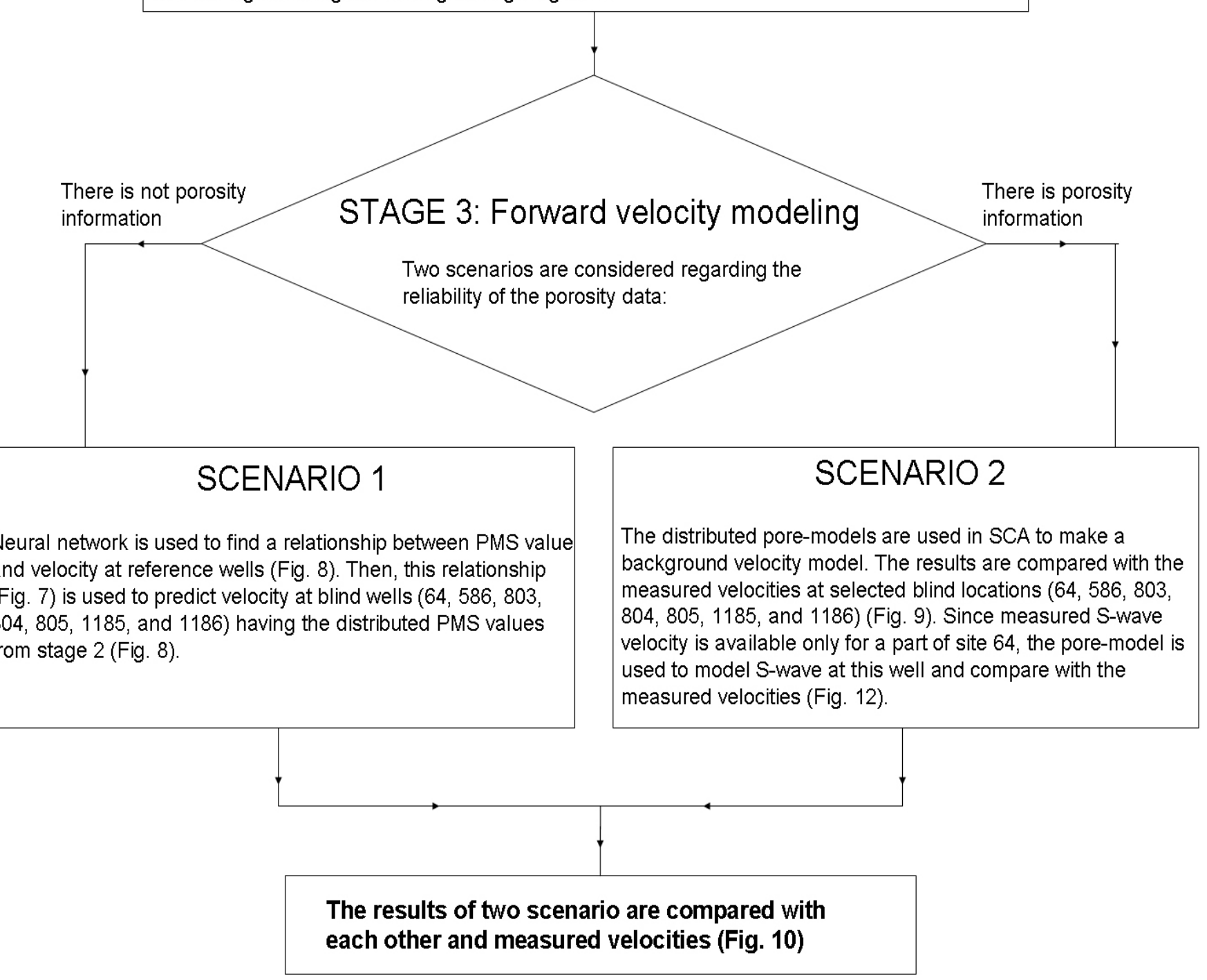

Fig. (5). The work flow applied in this paper for constructing a background velocity model and velocity prediction.

cube (Fig. 5, stage 2). Furthermore, the constructed poremodel cube is used to model the velocities at seven so-called blind wells (sites $64,586,803,804,805,1185$ and 1186) (Fig. 5, stage 3) and finally the results are compared with their measured plug velocities, and some theoretical rock physics models. Fig. (5) shows the workflow applied during the rest of the paper for constructing the background velocity model and the velocity estimation at the positions of the blind wells. 
Table 1. Rock Types for Reference Wells (Site 288, 289,807, 1183, and 1184) $[11,34,36]$. Depths are in Meter Below Sea Floor (MBSF)

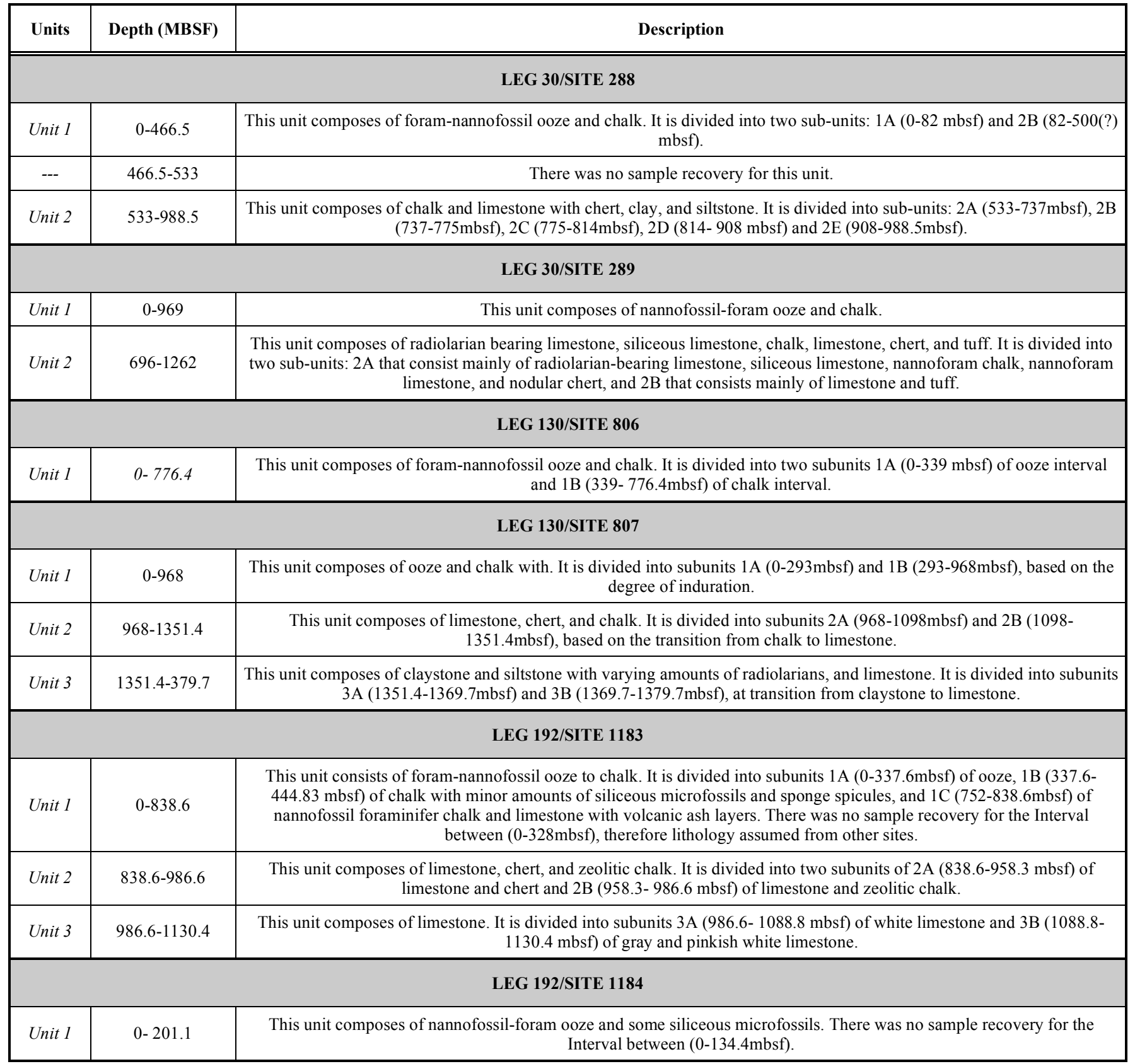

\section{STAGE ONE: PORE ASPECT RATIO MODELING}

Sites $288,289,806,807,1183$, and 1184 are considered as reference sites for construction of the pore-model cube since they have a good penetration into the sedimentary column (Table 1) as well as a good areal coverage on the Ontong Java Plateau. They are chosen to provide a basis for the geology-guided evaluation of pore-models versus depth. Subsequently, the SCA was used to model the effective moduli of mono-mineralogical chalk (Table 3). This procedure (cf. [10]) was applied to the sites 288, 289, 806, 807,1183 and 1184 and the corresponding pore-models for these sites were determined. A comparison between the modelled and measured velocities is shown in Fig. (6). The good match between the modelled and measured velocities confirms that the applied pore-models are appropriate at well locations.

\section{STAGE TWO: GEO- AND PROPERTY MODELING}

The aim of reservoir characterization is to gain information about the spatial variations of lithofacies and their petrophysical properties (e.g. porosity, permeability etc.) as well as to obtain information about the geometry of geobodies. Output from such studies may provide a spatially varying model where the petrophysical properties are defined in a $3 \mathrm{D}$ gridded model.

Based on the sea-floor depth and ooze, chalk, and limestone thicknesses from all of the penetrating wells into the Ontong Java Plateau (sites 64, 288, 289, 586, 803, 804, 
Table 2. Rock Types for Blind Wells (Site 64, 586, 803, 804, 805, 1185, and 1186) $[11,34,36-38]$. Depths are in Meter Below Sea Floor (MBSF).

\begin{tabular}{|c|c|c|}
\hline Units & Depth (MBSF) & Description \\
\hline \multicolumn{3}{|r|}{ LEG 7/SITE 64} \\
\hline Unit 1 & $0-513.5$ & $\begin{array}{l}\text { This unit composes of foram-nannofossil chalk and ooze with radiolarians. The first } 150 \mathrm{~m} \text { of the sediment consist is very } \\
\text { soft to soft sediments. }\end{array}$ \\
\hline Unit 2 & 513.5- 971 & This unit composes of nannofossil chalk and limestone to nannofossil chalk with radiolarians. \\
\hline \multicolumn{3}{|r|}{ LEG 89/SITE 586} \\
\hline Unit 1 & $0-969$ & $\begin{array}{l}\text { This unit composes of nannofossil-foram ooze and chalk. It is divided into two subunits } 1 \mathrm{~A}(0-320 \mathrm{mbsf}) \text { of ooze and 2B } \\
\qquad(320-969 \mathrm{mbsf}) \text { of chalk and ooze. }\end{array}$ \\
\hline Unit 2 & $969-1262$ & $\begin{array}{l}\text { This unit composes of radiolarian bearing limestone, siliceous limestone, chalk, nannofossil-foram limestone, nodular chert } \\
\text { and tuff. It is divided into subunit } 2 \mathrm{~A}(969-1231 \mathrm{mbsf}) \text { of radiolarian bearing limestone, siliceous limestone, chalk, } \\
\text { nannofossil-foram limestone, nodular chert, and 2B (1231-1262mbsf) of limestone and tuff. }\end{array}$ \\
\hline \multicolumn{3}{|r|}{ LEG 30/SITE 803} \\
\hline Unit 1 & $0-563.7$ & $\begin{array}{l}\text { This unit composes of nannofossil ooze and chalk to foram-nannofossil ooze and chalk. It is divided into subunits } 1 \mathrm{~A}(0- \\
\qquad 217.1 \mathrm{mbs}) \text { of ooze and } 1 \mathrm{~B}(217.1-563.7 \mathrm{mbsf}) \text { of chalk. }\end{array}$ \\
\hline Unit 2 & $563.7-621.8$ & This unit composes of approximately $58 \mathrm{~m}$ of chalk with radiolarians. \\
\hline Unit 3 & $621.8-626.3$ & This unit composes of claystone and clayey siltstone, with minor radiolarian. \\
\hline \multicolumn{3}{|r|}{ LEG 30/SITE 804} \\
\hline Unit 1 & $0-313$ & $\begin{array}{l}\text { This unit composes of ooze and chalk. Foraminifers and radiolarians generally are present in abundance of less than } 25 \% \text {. } \\
\text { This sequence can be divided into subunits } 1 \text { A ( } 0-181 \mathrm{mbsf}) \text { of ooze with radiolarians and 1B (181-313mbsf) of chalk with } \\
\text { radiolarian. }\end{array}$ \\
\hline \multicolumn{3}{|r|}{ LEG 30/SITE 805} \\
\hline Unit 1 & $0-616$ & $\begin{array}{l}\text { This unit composes of nannofossil-foram ooze and chalk. Ash layers, clays, quartz, and feldspars are the important } \\
\text { impurities. It is divided into subunits 1A (0-293.7mbsf) of nannofossil-foram ooze and 1B (293.7-611 mbsf) of nannofossil- } \\
\text { foram chalk. }\end{array}$ \\
\hline \multicolumn{3}{|r|}{ LEG 192/SITE 1185} \\
\hline Unit 1 & $0-250.60$ & $\begin{array}{c}\text { There was no sample recovery for this interval. However, Tertiary sedimentary history similar to other sites on the Ontong } \\
\text { Java Plateau has been assumed for this interval. }\end{array}$ \\
\hline \multicolumn{3}{|r|}{ LEG 192/SITE 1186} \\
\hline Unit 1 & $0-812.7$ & $\begin{array}{c}\text { There was no sample recovery for the interval between (0-697.4). However, Neogene-Oligocene chalk and ooze has been } \\
\text { assumed for this interval. }\end{array}$ \\
\hline Unit 2 & $812.7-968.6$ & This unit composed of chalk and limestone. \\
\hline
\end{tabular}

$805,806,807,1183,1184,1185,1186$ and 1187), a simple geo-model of the plateau was made. This model gives a conceptual picture of the area as no seismic data were available. Then, properties like porosity from the wells were distributed within the grid using a moving average algorithm. The moving average algorithm computes a weighted mean average where the weights are a function of distances from the actual data points (in this paper, the weights are the inverse distance squared). Output gives thickness variations for ooze, chalk and limestone at the different locations.

Here the gridded model consists of 9473464 cells $(170 \times 309 \times 183$ nodes $)$. In order to be able to distribute the evaluated pore aspect ratios at well locations along with

Table 3. Elasticity Data Selected on the Basis of Citation in Fabricius [39]. $\rho=$ Density, $K=$ Bulk Modulus, $M=P-W a v e ~ M o d u l u s$, and $G=$ Shear Modulus, $V_{p}=$ P-Wave Velocity, $V_{s}=$ S-Wave Velocity

\begin{tabular}{|c|c|c|c|c|c|c|}
\hline Mineral & $\boldsymbol{\rho}\left(\mathrm{gcm}^{-3}\right)$ & $\boldsymbol{K}(\boldsymbol{G P a})$ & $\boldsymbol{M}(\mathrm{GPa})$ & $\boldsymbol{G}(\mathrm{GPa})$ & $\boldsymbol{V}_{p}\left(\boldsymbol{m s} \boldsymbol{s}^{-1}\right)$ & $\boldsymbol{V}_{\boldsymbol{s}}\left(\mathrm{ms} \mathbf{s}^{-1}\right)$ \\
\hline \hline Calcite & 2.71 & 71 & 111 & 30 & 6400 \\
Water & 1.02 & 2.3 & 2.3 & 0 & 1500 \\
\hline
\end{tabular}


(a)

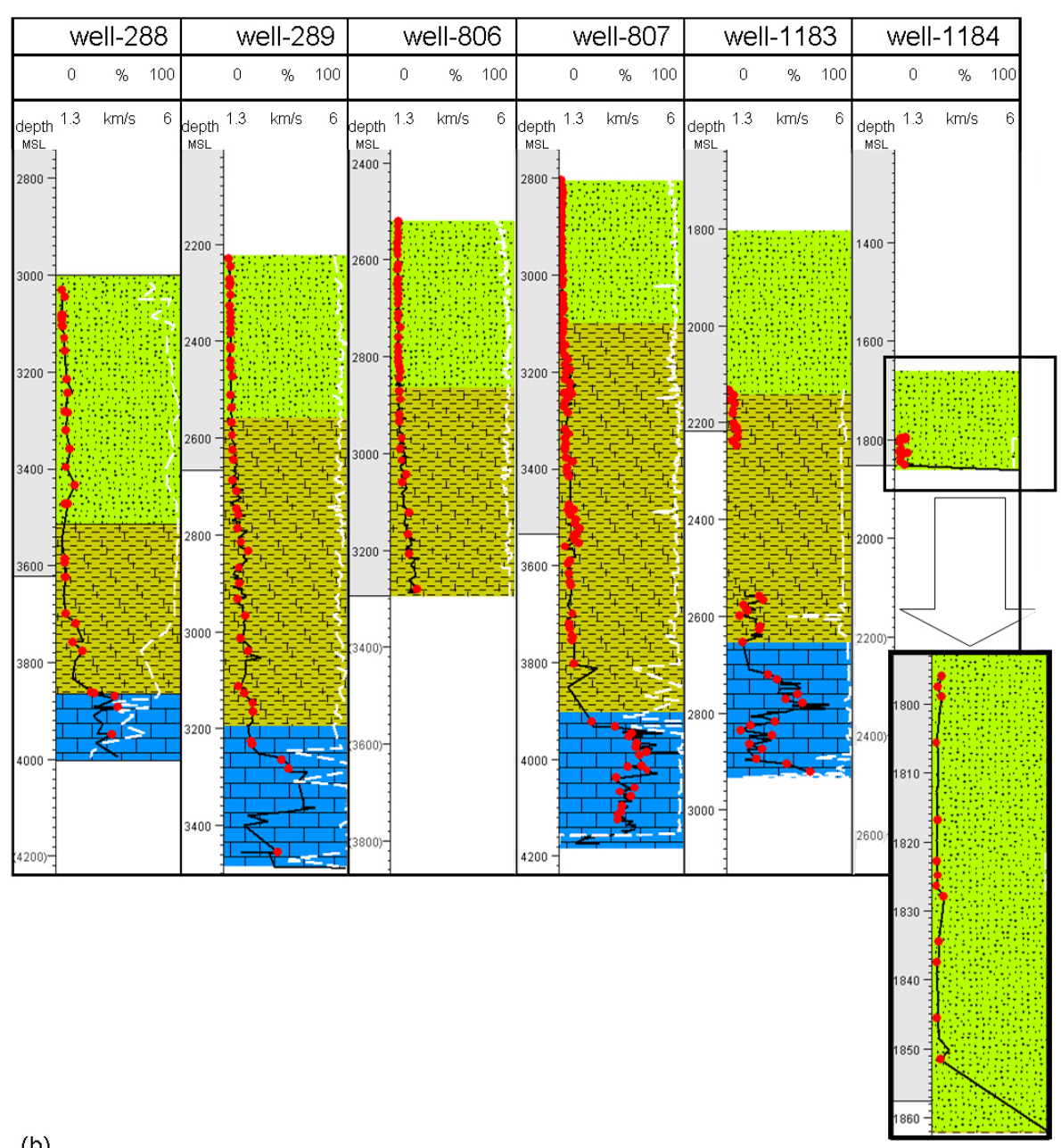

(b)

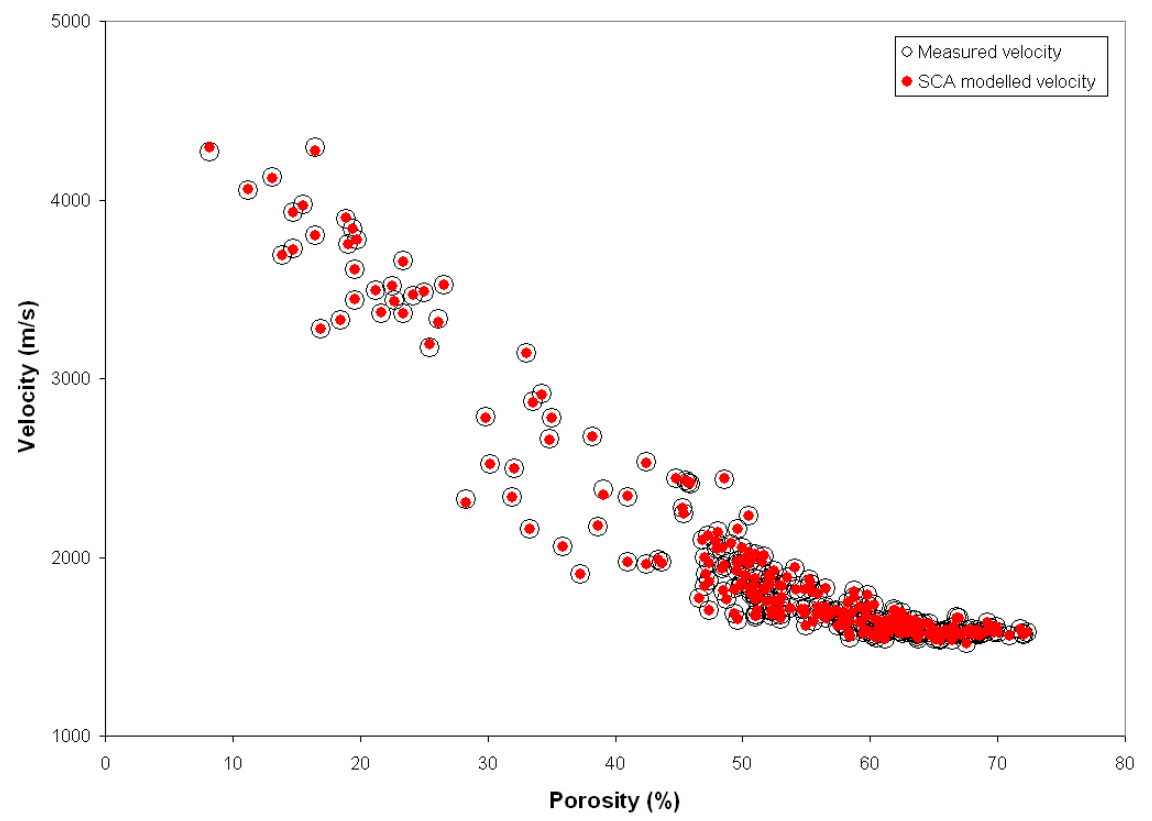

Fig. (6). (a) Comparison between modelled and measured velocities at each well location and (b) for all the reference wells in one cross plot. Red circles denote modelled velocities using SCA and an adopted pore-model using geological input. Measured velocities are shown by the black line (a) and black open circles (b). Velocity data are not available in the depth interval of 2260-2560msl at site 1183. Ooze, chalk and limestone intervals are shown with green, yellowish green and blue colors, respectively. Carbonate percentage is shown by the white line. Depths are below Mean Sea Level (MSL). 
other well properties (i.e. porosity, carbonate content etc.) through the whole model, we consider the normalized pore aspect ratios as the well property. Normalization of the pore aspect ratios help to keep the total percentage of different aspect ratio concentrations, $\Sigma F_{m}\left(\alpha_{i}\right)$ equal to $100 \%$ for each cell during the property modeling. Since our rock physic model was restricted to a mineralogically uniform chalk (Table 3), the cells with carbonate less that $80 \%$ were rejected.

\section{STAGE THREE: FORWARD VELOCITY MODELING}

The result of stage two is a $3 \mathrm{D}$ cube where the poremodels vary with depth. Now, this cube can be used as input to the SCA modeling at the so-called blind sites 64,586 , $803,804,805,1185$ and 1186 . Geology core analysis for all rock types at these sites are given in Table 2 .

Although porosity plays an important role in velocity modeling, still a good porosity model is a challenge to obtain, especially for locations far from the wells. This means that an uncertainty in the derived porosity cube will be transferred into the velocity modeling. This issue is important especially in inversion problems where velocities are used to predict porosities. Therefore, we test two scenarios regarding the availability of porosity data. First one is to consider when the porosity data is not available, and as a result can not to be directly used in the velocity modeling procedure. In the second scenario, we also use porosity information to predict velocities. Finally we compare the results of these two scenarios.

In scenario one, we compare predicted velocities at blind wells using interpolation velocities directly, and via interpolation using a so-called pore-model stiffness (PMS) parameter. But, in scenario two, we assume that reliable porosity data are available to be used for velocity prediction. Here, we compare the results obtained using various standard rock physics models (e.g. HS, Voigt and Ruess) and an inclusion based model (SCA) using measured plug porosities. The obtained $3 \mathrm{D}$ spatially varying pore-model cube (stage 2) is used as an input in SCA. In the following these two scenarios are discussed in detail:

1) Building a velocity model based on well data and geometrical constraints: We use a moving average algorithm to predict velocities at blind wells as our first approach in this scenario. Our second approach is to use the 3D pore-model cube to predict velocities via the PMS parameter. At a specific depth point $\mathrm{m}$ the PMS value is defined by

$$
(P M S)_{m}=\left[\frac{1}{N} \sum_{i=1}^{N}\left(F_{m}\left(\alpha_{i}\right) \alpha_{i}\right)^{2}\right]^{1 / 2}
$$

where $\mathrm{N}$ is the number of pore aspect ratios in the pore-model (cf. [10])

Actually, this value expresses an overall effect of all the pore aspect ratios in the rock on the velocity variation. Since the pore aspect ratios are deduced from porosity and velocity data at the reference wells, they are considered to reflect the impact of depositional and post-depositional processes in the area. PMS increases with increasing amount of spheroidal pores (i.e. $\alpha=1$ ) and decreases with increasing amount of crack porosity (i.e. $\alpha=0.001$ ). Implicitly PMS reflects both changes in pore type and porosity, and their related effects on velocity. Thus, Using PMS makes the interpolation somewhat geology dependent.

An artificial neural network is now used to find a relationship between the PMS and velocity using the data at the reference wells (Fig. 7). This is obtained by splitting the available information into two parts. One being used for the training and the other used to calculate the errors. Then these calculated errors are propagated backwards through the network to adjust the applied weights on the training part, so that the errors would be reduced if the same input was used on a second trial. This procedure continues until we get the minimum possible error and optimal weights.

These optimal weights can now be used to predict velocity from the PMS and thus the pore type parameters at the blind wells. Fig. (7) displays a crossplot of the velocities versus PMS values for the sites 288, 289, 806, 807, 1183 and 1184 both for known wells (colored circles) and for the trained model (open circles). The color variation shows the porosity variations with depth. Subsequently the obtained relation is used as input into a neural network algorithm for the velocity prediction at blind wells.

Fig. (8) compares the velocity prediction using the neural network algorithm (combined with the spatially varying pore-model) (red stipple-dot line) with the spatial velocity interpolation using moving average at sites $64,586,803,804,805,1185$ and 1186 (blue dashed line) together with their measured up-scaled (arithmetic mean) velocities (black solid line) from plug velocities. For the ooze interval predicted and measured velocities are close (Fig. 8). In the chalk (and limestone intervals; well 1186) the moving average interpolation gives velocities much higher than the measured (except site 586), while using neural network interpolation together with the PMS cube prediction coincide fairly well with the observations. The errors in the interpolated velocities may be a result of the assumed stratigraphic distribution of layers using wells. Because an incorrect placing of lithofacies borders (ooze, chalk and limestone) respectively may cause an artificial jump in velocities, compared to results obtained using the correct borders. The use of the interpolated PMS value seems to give results less sensitive to changes in borders due to the differences in the layer thickness and porosity. This can be related to the fact that porosity data was incorporated into the PMS value at reference wells.

2) Building a velocity model based on well data, geometrical constraints and including porosity: In this scenario, we use the porosity data at the blind wells to test for the accuracy in the prediction. The velocity modeling was performed using moving average interpolated pore-models and core plug 


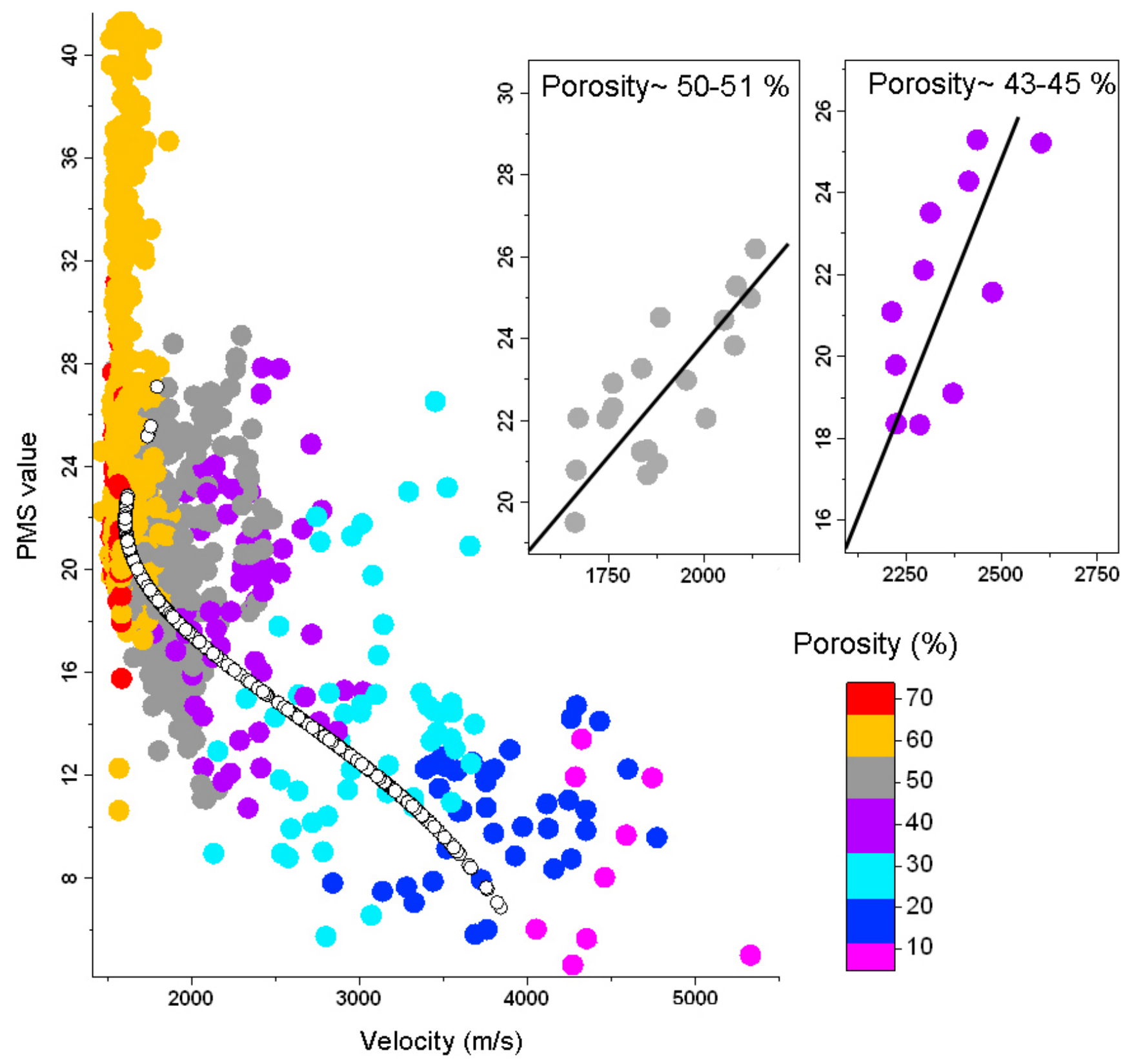

Fig. (7). Crossplot of the PMS-velocity relationship for reference wells (filled circles) and the trained relationship (open circles) used for velocity prediction at blind wells. The PMS value is governed by both velocity and porosity. In theory, for a given porosity, velocity increase with increasing PMS value [10]. To show this concept in our dataset, we divide porosity into smaller intervals (colors). Porosity can be considered constant in very small intervals, therefore, this trend can be seen more clearly (small plots at the upper part of the picture). However, near the critical porosity (velocity 1550ms-1) (ooze interval) (red to ochre and yellowish colors), for almost fixed porosity and velocity, there are different PMS values. This mainly relates to the percentage of forams at deposition (ooze) such that higher PMS values indicate higher percentages of foraminifera. This means that, around the critical porosity the PMS values is mainly governed by the foraminifera content which is again a function of the depositional environment. Hence, at porosities around the critical porosity, the PMS value reflects the depositional texture rather than diagenetic conditions [10]. On the other hand, for a given velocity, the porosity and PMS value relationship is more complex. In our dataset, the combination of these two factors (porosity and velocity) results in decrease in the PMS value by increasing velocity (trained relationship; open circles). Therefore, PMS values contain information about velocity, porosity and pore types, and may be assigned for different lithofacies (ooze, chalk, and limestone).

porosities as input to the SCA modeling. In addition, the HS-upper bound, time-average and Reuss models are presented. Fig. (9) shows this comparison, including SCA (red circles), HS-upper bound (gray dashed line), time-average (blue dashed line) and Reuss boundary (purple stipple-dot line) along with the measured plug velocities (black solid line) for sites 64, 586, 804, 805, 1185 and 1186. The results demonstrate that by including pore aspect ratio models, the velocity predictions improve. The good match between SCA and measured velocities may indicate a homogeneous pore texture in this area. 


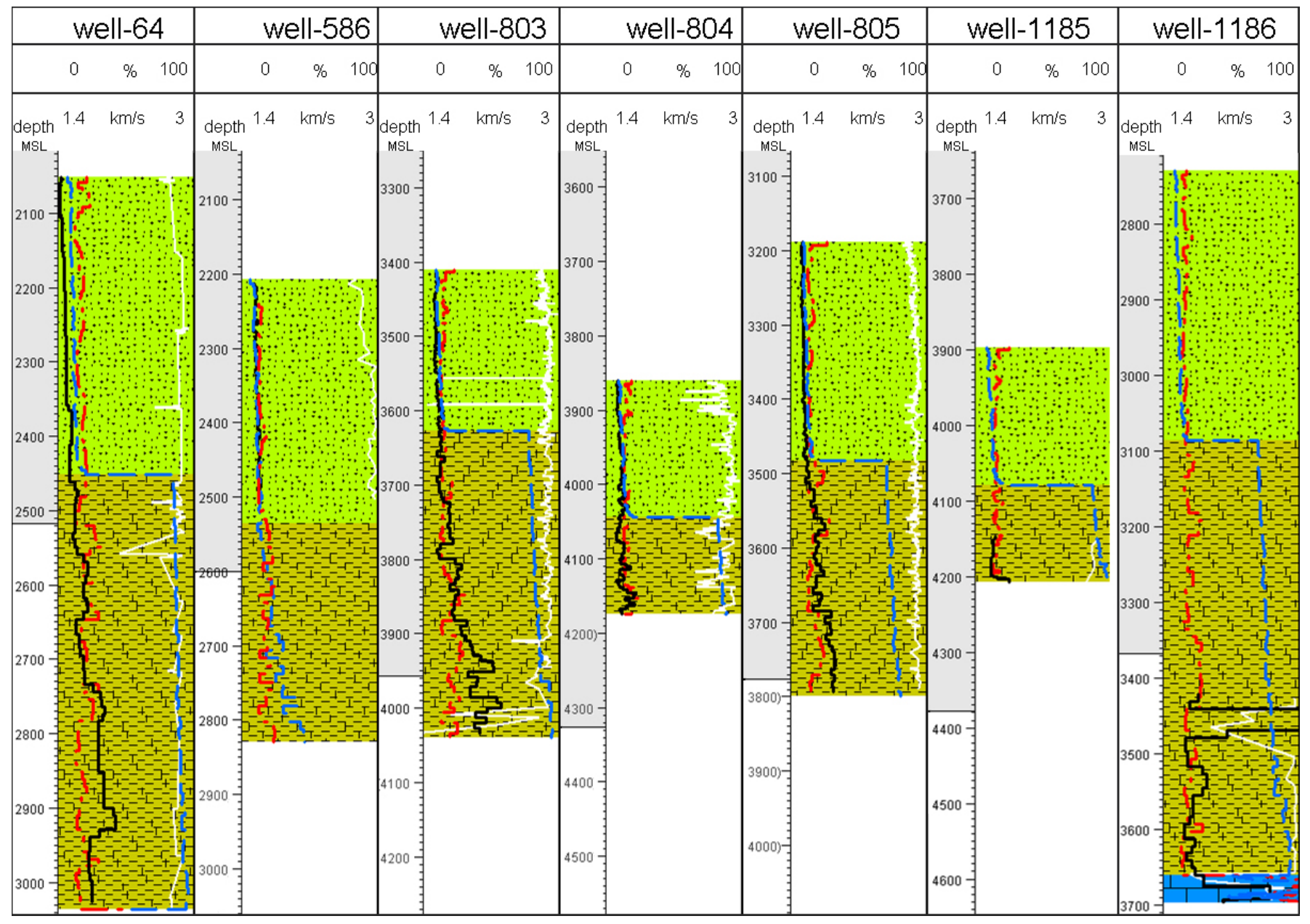

Fig. (8). Using the trained PMS-velocity relation in Fig. (7, open circles) and the spatially varying pore-model in velocity prediction of blind wells (red dashed line). Comparison is made with measured up-scaled plug velocity (black solid line) (arithmetic mean) and interpolated moving average velocity from reference wells (blue stipple-dot line). A better match is observed between neural network velocity derived and measured velocity. Ooze, chalk and limestone intervals are shown with green, yellowish green and blue colors, respectively. Carbonate percentages are shown by the white line. Depths are below Mean Sea Level (MSL).

\section{DISCUSSION OF RESULTS}

The applied pore-models at some reference wells are calibrated with the post-depositional states of the pelagic carbonates at those wells. Velocity profiles were predicted at other locations using these pore-models when distributed spatially within the whole area. This means that the spatially varying $3 \mathrm{D}$ cube of aspect ratios can adopt information about post-depositional processes in the area. This basically suggests that geology information may be used to constrain the velocity prediction. In this paper, we applied a poremodel cube with and without porosity data to predict velocity.

Fig. (10) compares the results of the two scenarios. It can be seen that in our dataset the porosity information does not really affect the quality of the velocity prediction. In some intervals where the porosity is used gives better results (e.g. sites 64 and 803), while in some other velocity predictions are less precise (e.g. site 1186). Anyway, both methods approximate the velocities at the blind wells fairly well. Comparisons (Figs. 8-11) confirm the constructive effects of taking into account geological constraints in velocity prediction of chalks.
Fig. (11) compares the SCA obtained velocities and the measured velocities along with the visual core description at each well site $[11,34,35]$. It can be seen that differences between the measured and the modelled velocities are mainly due to the changes in mineralogy (site 1186) or external factors such as drilling fluids (site 803 and the bottom interval of site 805). At site 1185 the main reason for the over-prediction of SCA velocities is due to the radiolarian contents (between 10-25\%); while microfractures observed on the plugs are the reason for misfit on site 804 . On the other hand, for some sites, like site 64 , big differences are observed between the measured and the modelled velocities for the first $500 \mathrm{~m}$ of the site $\left(\sim 200 \mathrm{~ms}^{-1}\right)$. The assumption of un-fractured, mono-mineralogical chalk saturated with brine is probably not correct at this depth level as been documented from visual core description revealing very soft to soft ooze and chalk.

The places with heavily bioturbation activities also show significant differences in velocities (site 804). This indicates the effect of bioturbation on re-arrangement of the pore geometries, and, thus, the pore-model and PMS. On the other hand, the modelled and measured velocities match with each other fairly well at sites $586,803,804,805$ (ooze and chalk 


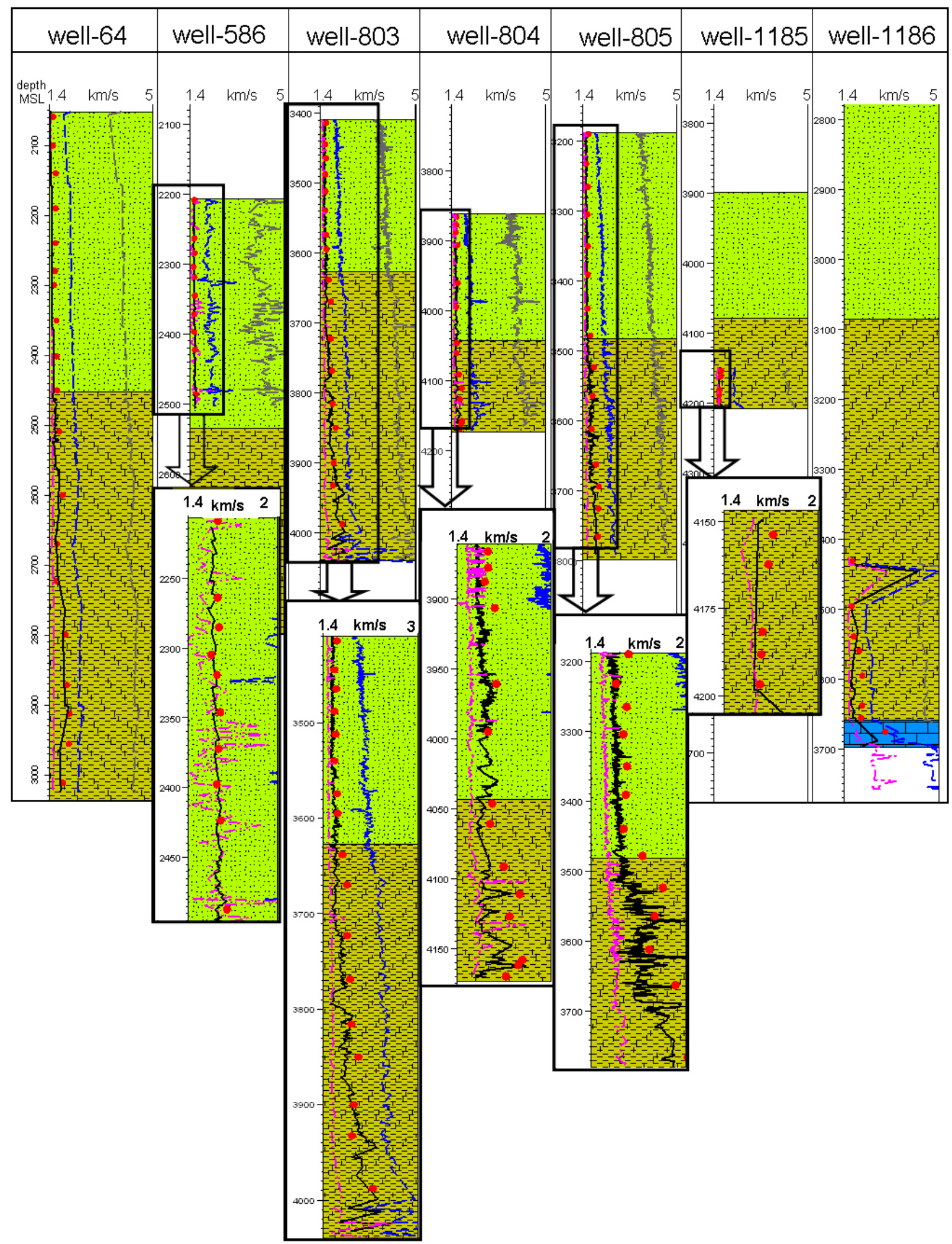

Fig. (9). Modelled velocities (scenario 2) at blind wells using SCA (red dots), HS (gray dashed line), time-average (blue dashed line), and Reuss boundary (purple stipple-dot line). The poremodel is from moving average interpolation using reference well pore-models. Depths are below Mean Sea Level (MSL). Black line and lithologies are defined in Fig. (8).

intervals), 64, and 1186 (chalk and limestone intervals). This may express the similarity in depositional and post- depositional conditions between these sites and the reference well sites (sites 288, 289, 806, 807, 1183 and 1184). 


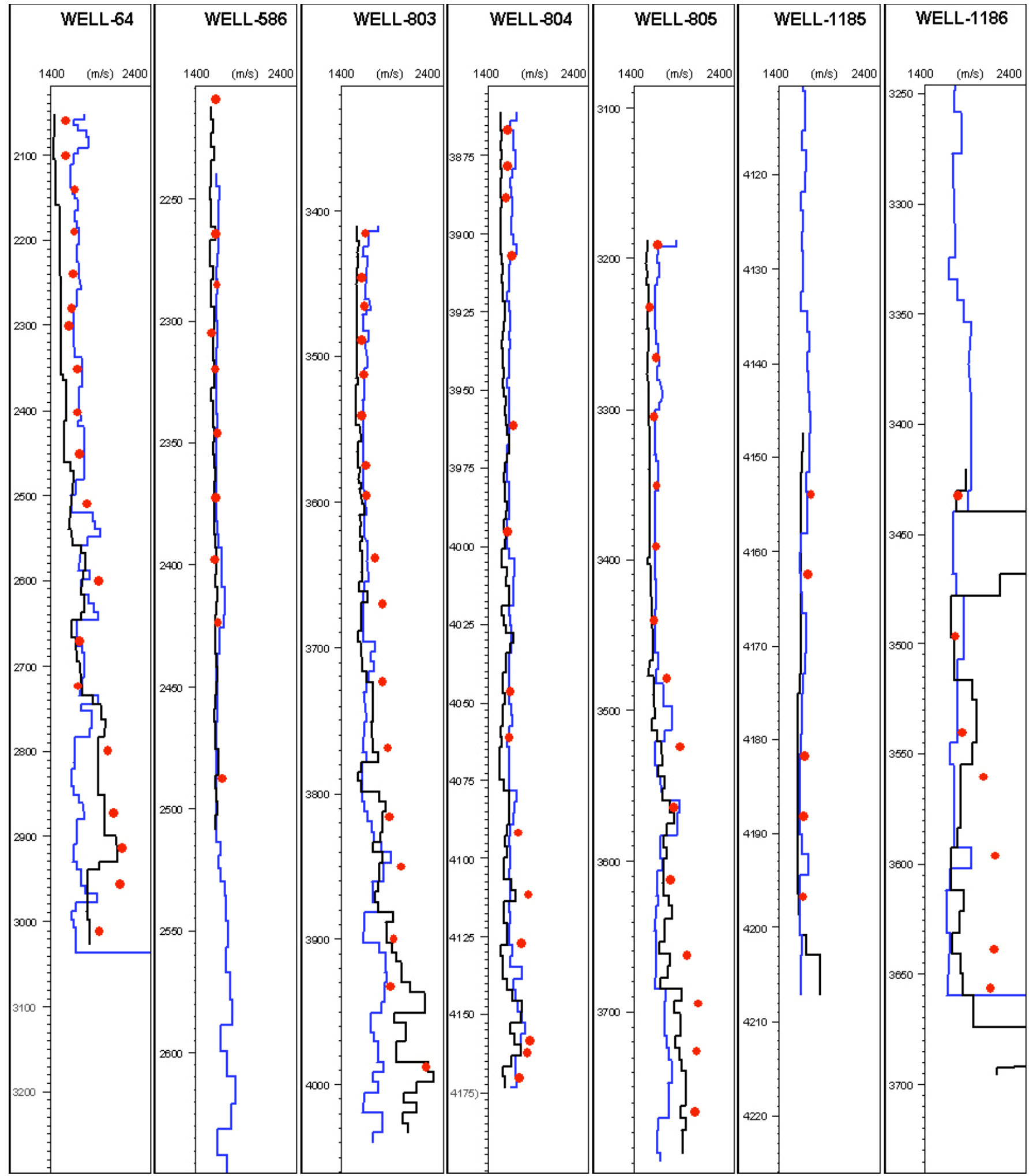

Fig. (10). Comparison between velocity modeling of two scenarios with up-scaled measured Pwave plug velocities (black solid line). In scenario one (blue solid line), porosity data was ignored. Neural network algorithm was used to find a relationship between PMS value and velocities. This relationship (Fig. 7) was finally used to predict velocity from distributed (moving average algorithm) PMS values at other well locations. In scenario two (red filled dots), plug porosity at each well sites was used along with a 3D pore-model as input to SCA velocity modeling.

The abovementioned approach can be used, furthermore, to assist seismic reservoir characterization and velocity interpretation. The application of such pore-model cubes can also be extended to construct background velocity cubes (from reference wells) and also prediction of $\mathrm{S}$-wave velocities. 

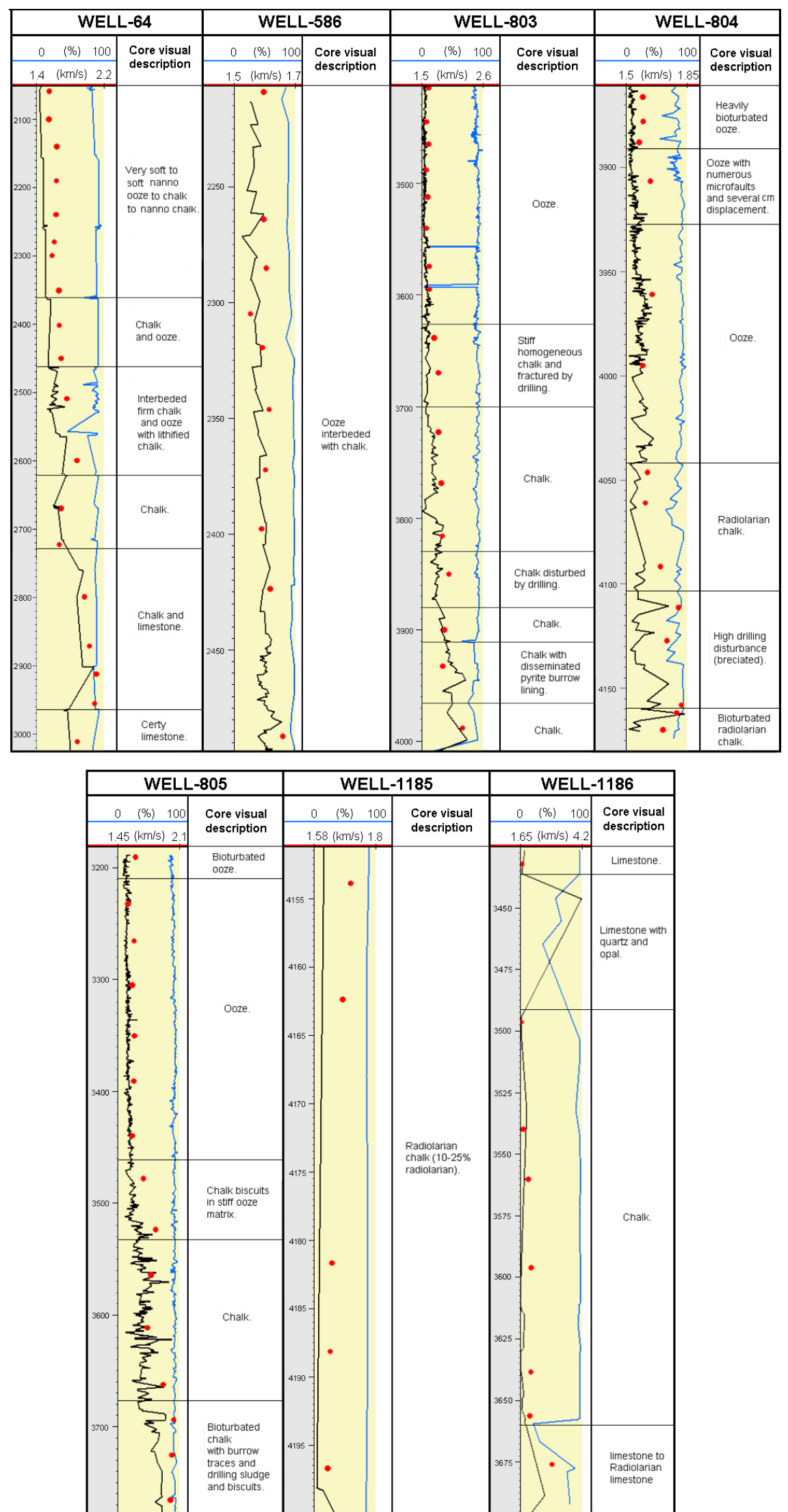

Fig. (11). Comparison between SCA modelled velocities (red dots) and measured plug velocities (black line). Carbonate content is shown for all the wells in blue line, and lithology definition is based on the visual description of the core material taken from the online Ontong Java Plateau sources [11,34,36,37,38]. This picture shows a good match between measured and SCA modelled velocities for the unfractured monomineralogical chalk saturated with brine intervals. Depths are below Mean Sea Level (MSL). 


\section{BACKGROUND VELOCITY CUBE}

We suggest that a background velocity cube can be constructed based on some reference wells followed by a three-step procedure. This velocity cube can be used to model velocity at other wells. Comparison between the background and the measured velocities may indicate changes in mineralogy, fluid or pore-model relative to reference wells. These differences can be defined as deviated logs. Later, these deviated logs can be interpreted for possible changes in mineralogy, fluid or pore-model (depositional and post-depositional processes) compared with the reference wells. Building a 3D spatial varying poremodel establishes a useful link between geological features and velocity data. Using well data along with the geology information is thus a key for building of such a cube.

\section{S-WAVE VELOCITY MODELING}

S-wave velocity information was available just for $500 \mathrm{~m}$ interval in well 64. However, we tried to use our 3D spatial varying pore-model for predicting the S-velocity in this interval. Fig. (12) compares the predicted $\mathrm{S}$ velocities (red points) to those measured on plugs (black solid line). The misfit are mainly related to the soft chalk at site 64 (two first modelled point velocities) and the mixture of limestone and chalk (bottom of the well). Anyway, the reasonable match between the predicted and measured velocities also confirms the applicability of this strategy for establishing an Svelocity cube of the area.

The modeling strategy used here is the one proposed by Saberi et al. [10] aiming to incorporate chalk diagenetic alterations into velocity modeling. However, Fabricius [6] addressed the similar problem using the so called approach isoframe model which employs a modified upper HashinShtrikman bound [22] as the rock physics model. This model considers critical porosity to narrow the elastic boundaries of a mixture between sediment particles and fluids. Furthermore, Olsen et al. [8] related isoframe values to the pore stiffness through the Biots coefficient. The isoframe model is relatively easy to link to lithological data and holds fewer assumptions than SCA. However, the modified upper Hashin-Shtrikman bound [22] assumes that all pores are spherical and homogenously mixed, thus ignores pore structure variations. Therefore, the assumed relation between pore stiffness and isoframe values [8] are indirect and accounted for through the matrix properties. Here, we relate the pore-model stiffness and the according elastic parameters to theoretical pore type distributions (pore-models) in chalks as a function of primary composition and subsequent diagenetic alterations through the PMS parameter. Thus, our approach facilitates a direct and robust link between pore stiffness, lithofacies, and elastic behaviour.

\section{CONCLUSIONS}

In this paper, we incorporate geological information and burial effects to constrain rock physics modeling of chalk velocities. The approach is to distribute the post-depositional state of the sediments at some reference wells to the whole area. This distribution is driven by a pore-type classification based on a geological description of the chalks. This

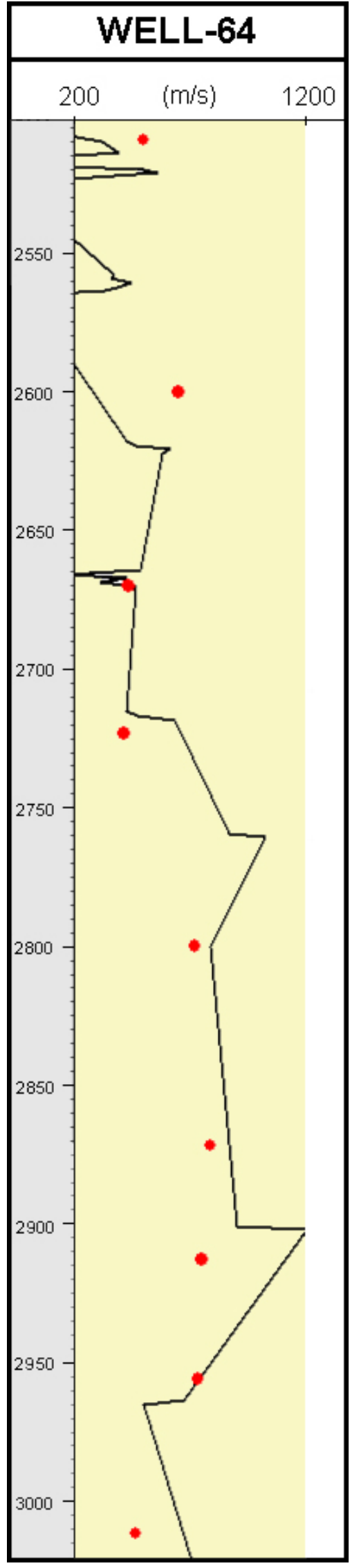

Fig. (12). S-wave modeling based on constructed three-dimensional pore-model from reference wells. 
classification enables us to define a pore model at each well site. Using a simple interpolation method, a spatially varying 3D cube of the pore-model can be constructed. This pore model implicitly adopts the geological information and can be used subsequently for the velocity modeling.

We also show the importance of using geological information when constructing a background velocity cube in chalks. From the geological setup, a pore model and the porosity are the key information for constructing such a cube. This means that potential places with different depositional and post-depositional histories may be highlighted as deviations from the background velocity cube.

\section{ACKNOWLEDGEMENTS}

This work was made in collaboration with IRIS and was funded by the Norwegian Research Council, ConocoPhillips, DNO International ASA, and Statoil ASA through the Petromax Program (project No. 163316-Carbonate Reservoir Geomodels).

\section{REFERENCES}

[1] G.P. Eberli and G.T. Beachle, "Factors controlling elastic properties in carbonate sediments and rocks", The Leading Edge, vol. 22, pp. 654-660, July 2003.

[2] P.A. Scholle, "Chalk diagenesis and its relationship to petroleum exploration: Oil from chalks, a modern miracle?" American Association of Petroleum Geologist Bulletin, vol. 61, pp. 982-1009, July 1977.

[3] E.L. Hamilton, R.T. Bachman, W.H. Berger, T.C. Johnson and L.A. Mayer, "Acoustic and related properties of calcareous deepsea sediments" Journal of Sedimentary Petrology, vol. 52, vol. 733-753, September 1982.

[4] D.M. Audet, "Modelling of porosity evolution and mechanical compaction of calcareous sediments", Sedimentology, vol. 42, pp. 355-373, April 1995.

[5] P. Japsen, "Regional velocity-depth anomalies, North Sea chalk: a record of overpressure and Neogene uplift and erosion", American Association of Petroleum Geologist Bulletin, vol. 82, pp. 20312074, November 1998.

[6] I.L. Fabricius, "How burial diagenesis of chalk sediments controls sonic velocity and porosity", American Association of Petroleum Geologist Bulletin, vol. 87, pp. 1755-1778, November 2003.

[7] L. Gommesen, I.L. Fabricius, T. Mukerji, G. Mavko and J.M. Pedersen,"Elastic behaviour of North Sea chalk: A well-log study", Geophysical Prospecting, vol. 55, pp. 307-322, May 2007.

[8] C. Olsen, K. Hedegaard, I.L. Fabricius and M. Prasad, "Prediction of Biot's coefficient from rock-physical modeling of North Sea chalk", Geophysics, vol. 73, pp. E89-E96, March-April 2008.

[9] G. Mavko, T. Mukerji and J. Dvorkin, The rock physics handbook: Cambridge, Cambridge university press, 1998.

[10] M.R. Saberi, T.A. Johansen and M.R. Talbot, "Textural and burial effects on rock physics characterization of chalks", Petroleum Geosciences, vol. 15, pp. 355-365, November 2009.

[11] E.M. Barbu (volume Ed.), "Proceedings of the Ocean Drilling Program", vol. 130, January-March 1990. Available: http://wwwodp.tamu.edu/publications/130_IR/130TOC.HTM [Accessed May $16,2009]$.

[12] J.W. Morse and F.T. Mackenzie, Geochemistry of sedimentary carbonates, Developments in Sedimentology, vol. 48, Elsevier, Amsterdam, 1990.

[13] P.A. Scholle, D.G. Bebout and C.H. Moore, Carbonate depositional environments: American Association of Petroleum Geologist Memoir, vol. 33, 1983.

[14] C.H. Moore, Carbonate reservoirs-porosity evolution and diagenesis in a sequence stratigraphic framework: Developments in Sedimentology, vol. 55, Elsevier, Amsterdam, 2001.

[15] N.P. Bramwell, G. Caillet, N. Meciani, N.C. Judge, M. Green and P. Adam, "Chalk exploration, the search for the subtle trap" in Petroleum Geology of North West Europe, Proceedings of the fifth conference, Eds. A.J. Fleet and S.A.R. Boldy: Geological Society of London, pp. 911-938, 1999.

[16] M.K. Borre and I.L Fabricius, "Chemical and mechanical processes during burial diagenesis of chalks: An interpretation based on specific surface data of deep-sea sediments", Sedimentology, vol. 45, pp. 755-769, August 1998.

[17] J. Grutzner and J. Mienert, "Physical property changes as a monitor of pelagic carbonate diagenesis: An empirically derived diagenetic model for Atlantic ocean basins", American Association of Petroleum Geologist Bulletin, vol. 83, pp. 1485-1501, September 1999.

[18] I.L. Fabricius and M.K. Borre, "Stylolites, porosity, depositional texture, and silicates in chalk facies sediments. Ontong Java Plateau-Grom and Tyra fields, North Sea", Sedimentology, vol. 54, pp. 183-205, February 2007.

[19] D.C. Kim and M.H. Manghnani, "Influence of diagenesis on the electrical resistivity and the formation factor of deep-sea carbonate sediments", Geo-Marine Letters, vol. 12, pp. 14-18, March 1992.

[20] S. Schlanger and R. Douglas, "The pelagic ooze-chalk-limestone transition and its implications for marine stratigraphy" in: Pelagic sediments: on land and under the sea, Special Publication of the International Association of Sedimentologist, K. Hsu and H.C. Jenkyns, Eds., 1974, vol. 1, pp. 117-148.

[21] I.L. Fabricius, "Chalk: composition, diagenesis and physical properties" Bulletin of the Geological Society of Denmark, vol. 55, pp. 97-128, March 2007.

[22] A. Nur, G. Mavko, J. Dvorkin, and D. Galmudi, "Critical porosity: A key to relating physical properties to porosity in rocks" The Leading Edge, vol. 17, pp. 357-362, March 1998.

[23] S. Schlanger, R.G. Douglas, Y. Lancelot, L. Doherty, T.C. Moore, T.C. and P.H. Roth, "Fossil preservation and diagenesis of pelagic carbonates from the Magellan Rise, central North Pacific Ocean", in: Initial Reports of the Deep Sea Drilling Project, P.H. Roth and J.R. Herring, Eds., vol. 17, pp. 407-427, April-May 1971. Available: http://www.deepseadrilling.org/17/dsdp_toc.htm [Accessed January 20, 2009].

[24] R. Agersborg, T.A. Johansen, M. Jakobsen, J. Sothcott, and A. Best, "Effects of fluids and dual-pore systems on velocities and attenuations of carbonates", Geophysics, vol. 73, pp. N35- N47, October 2008.

[25] M. Wyllie, A.R. Gregory and G.H.F. Gardner, "Elastic wave velocities in heterogeneous and porous media", Geophysics, vol. 21, pp. 41-70, January 1956.

[26] A. Reuss,"Berechnung der fliessgrenzen von mischkristallen auf grund der plastizitatsbedingung fur einkristalle", Zeitschrift fur angewandte mathematic und mechanic, vol. 9, pp. 49-58, September 1929.

[27] W. Voigt, Lehrbuch der Kristallphysik, Teubner, Leipzig, Berlin, 1928.

[28] J.G. Berryman, “ Long-wavelength propagation in composite elastic media I. Spherical inclusions", Journal of Acoustic Society of America, vol. 68, pp. 1809-1819, December 1980.

[29] J.G. Berryman," Long-wavelength propagation in composite elastic media II. Ellipsoidal inclusons", Journal of Acoustic Society of America, vol. 68, pp. 1809-1819, December 1980.

[30] Z. Hashin and S. Shtrikman, "A variational approach to the theory of elastic behaviour of multiphase materials" Journal of Mechanical Physics Solids, vol. 11, pp. 127-140, March 1963.

[31] G.T. Kuster and M.N. Toksöz, "Velocity and attenuation of seismic waves in two-phase media: Part I. Theoretical formulations", Geophysics, vol. 39, pp. 587-606, October 1974.

[32] M. Jakobsen, T.A. Johansen and C. McCann, "The acoustic signature of fluid flow in a complex porous media", Journal of Applied Geophysics, vol. 54, pp. 219-246, December 2003.

[33] R. Agersborg, T.A. Johansen and M. Jakobsen, "Velocity variations in carbonate rocks due to dual porosity and waveinduced fluid flow", Geophysical Prospecting, vol. 57, pp. 81-98, January 2009.

[34] J.E. Andrews, G. Packham and J. Herring (Science Eds.),"Initial Reports of Deep Sea Drilling Project", vol. 30, April-June 1973. Available: http://www.deepseadrilling.org/30/dsdp_toc.htm [Accessed May 10, 2009].

[35] R.E. Boyce," Physical Properties - Methods", in: initial reports of the Deep Sea Drilling Project, N.T. Edgar, A.G. Kaneps and J.R. Herring, Eds. December 1970, February 1971, vol. 15, pp. 1115- 
1127. Available: http://www.deepseadrilling.org/15/dsdp_toc.htm [Accessed October 15, 2008].

[36] J.G. Fitton, J.J. Mahoney, P.J. Wallace and A.D. Saunders (Eds. board), "Proceedings of the Ocean Drilling Program", vol. 192, September-November 2000. Available: http://wwwodp.tamu. edu/publications/192_SR/192TOC.HTM [Accessed June 20, 2009].

[37] E.L. Winterer, W.R. Ricdel, P- Bronnimann, E.L. Gealy, G.R. Heath, L. Kroenke, E. Martini, R. Moberly, J.J. Resig and T. Worsley, "Initial Reports of the Deep Sea Drilling Project", vol. 7, August-September $1969 . \quad$ Available: http://www.deepseadrilling.org/07/dsdp toc.htm [Accessed April $12,2009]$.
[38] S. Orlofsky Ed., "Initial Reports of the Deep Sea Drilling Project," vol. 89, October-November 1982. Available: http://www.deepseadrilling.org/89/dsdp toc.htm [Accessed March 30, 2009].

[39] I.L. Fabricius, "Porosity loss in chalk facies sediments by physical compaction or by cementation- Consequences for P-wave modulus" Extended abstract presented at the annual meeting of American Association of Petroleum Geologist Meeting, Houston, Texas, 10-13 March 2002.

[40] W.H.F. Smith and D.T. Sandwell, "Global seafloor topography from satellite altimetry and ship depth sounding", Sciences, vol. 277, pp.1957-1962, September 1997.

(C) Saberi et al.; Licensee Bentham Open.

This is an open access article licensed under the terms of the Creative Commons Attribution Non-Commercial License (http://creativecommons.org/licenses/by-ne/ 3.0/) which permits unrestricted, non-commercial use, distribution and reproduction in any medium, provided the work is properly cited. 